\title{
PATOLOGIAS DAS CONSTRUÇÕES EM CONCRETO ARMADO: ESTUDO DE CASO DO EDIFÍCIO HISTÓRICO DA ESCOLA POLITÉCNICA DE PERNAMBUCO
}

\author{
E. J. M. LINS \\ Engenheiro Civil \\ Univ. de Pernambuco \\ Pernambuco; Brasil \\ eduardojmlins@hotmail.com
E. C. B. MONTEIRO
Engenheira Civil
Univ. de Pernambuco/Univ. Católica de Pernambuco
Pernambuco; Brasil
eliana@poli.br

\author{
M. C. P. PEDROSA JUNIOR \\ Engenheiro Civil \\ Univ. de Pernambuco \\ Pernambuco; Brasil \\ mcpj_pec@poli.br \\ A. C. LORDSLEEM JÚNIOR \\ Engenheiro Civil \\ Univ. de Pernambuco \\ Pernambuco; Brasil \\ acasado@poli.br
}

\section{RESUMO}

O Casarão Rosa da POLI, com seus 82 anos de idade, possui grande valor histórico para a instituição, tendo em vista ter sido o local no qual a escola de engenharia iniciou as suas atividades no Campus Benfica. O edifício é estruturalmente composto, essencialmente, por alvenaria estrutural, e possui 18,0\% da sua área com estruturas de concreto armado, as quais foram incorporadas ao longo do tempo. Foram realizadas inspeções visuais nos elementos em concreto armado do edifício, nos meses de setembro e novembro de 2019, com a finalidade de identificar as manifestações patolológicas e, emitir um diagnóstico, bem como propor ações para a recuperação das estruturas de concreto armado do Casarão. Os resultados obtidos permitem compreender que os problemas críticos nas estruturas são pontuais, especialmente nas vigas quem compõem a caixa de escadas da fachada sul. Ações de recuperação das estruturas devem ser tomadas de forma breve, sob pena do aumento dos custos para e recuperação estrutural. Um plano de manutenção para as estruturas de concreto armado é sugerido, visando manter o Casarão Rosa com um bom desempenho e uso pleno.

Palavras-chave: concreto armado, edifícios históricos, manifestações patológicas, plano de manutenção.

\section{ABSTRACT}

The 82-year-old Pink Mansion of POLI has great historical value for the institution, as it was the place where the engineering school began its activities at Campus Benfica. The building is structurally composed mainly of structural masonry, and has $18.0 \%$ of its area with reinforced concrete structures, which were incorporated over time. Visual inspections were performed on the reinforced concrete elements of the building, in September and November 2019, in order to identify the pathological manifestations and to issue a diagnosis, as well as to propose actions for the recovery of the Mansion reinforced concrete structures. The results allow us to understand that the critical problems in the structures are specific, especially in the beams that make up the stairway of the south façade. Structural restoration actions should be taken shortly, otherwise the cost of structural restoration will increase. A maintenance plan for reinforced concrete structures is suggested to keep the Pink Mansion performing well and in full use.

Keywords: reinforced concrete, historic buildings, pathological manifestations, maintenance plan.

\section{INTRODUÇÃO}

O homem vive em ambientes construídos, os quais estão em constante processo de envelhecimento e, com diversos problemas devido à baixa frequência ou à falta de manutenção, sendo a implementação de um eficiente plano de manutenção para as edificações essencial ao avanço para a um futuro ambientalmente sustentável (RAKHA e GORODETSKY, 2018).

No Brasil, a falta de cuidado com os edifícios, particularmente com a manutenção do ambiente construído, seja na fase de projeto, execução e uso, é conduta que em regra não integra o planejamento das obras e do uso, fazendo com que o risco de colapso estrutural dessas obras civis seja crescente ao longo dos últimos anos. As estruturas de concreto 
tornaram-se protagonistas na análise de patologias das edificações, uma vez que o concreto armado é um material que, sob o efeito de intempéries, somado à agressividade do meio e, sem manutenção periódica, certamente sofrerá deterioração, a qual desencadeiará manifestações patológicas nocivas aos edifícios.

O crescente número de eventos de colapso estrutural de edifícios no Brasil reafirmam a necessidade de serem adotadas medidas para o enfrentamento deste complexo problema, a exemplo do desmoronamento ocorrido no mês de outubro de 2019, após o início das obras para a recuperação estrutural do habitacional Edifício Andrea com quinze pavimentos, localizado na cidade de Fortaleza/CE, no qual nove pessoas morreram e sete foram resgatadas com vida (G1, 2019), ou ainda, do colapso ocorrido no mês de abril de 2019, após chuvas intensas, dos dois Edifícios do Condomínio Figueiras do Itanhangá com cinco pavimentos cada, localizados na comunidade da Muzema, cidade do Rio de Janeiro/RJ, no qual 24 pessoas morreram e dezenas ficaram desabrigados (EBC, 2019).

Edifícios históricos ou emblemáticos têm valor estético e arquitetônico únicos, além das funções específicas para os quais foram concebidos e, por consequência, demandam uma abordagem especial no tocante à conservação predial, reparo, recuperação e reforço estrutural, ou ainda quando do restauro de elementos construtivos singulares que os compõem (KAAMIN et al., 2017).

O desempenho de uma edificação está diretamente relacionado ao comportamento em uso do prédio e de seus sistemas, bem como às condições de exposição. As condições de exposição são função do conjunto de ações atuantes sobre a edificação, incluindo cargas gravitacionais, ações externas e ações resultantes da ocupação (CBIC, 2013).

Além dos incômodos causados pela necessidade de intervenção em uma estrutura para sua recuperação, um dos fatores mais relevantes a ser observado é, normalmente, o elevado custo para a excução das obras de reabilitação. Conquanto, quanto mais cedo um problema na estrutura de um edifício for identificado, mais fácil e mais barata será a execução das obras de recuperação e/ou reforço (BRUGOS et al., 2019).

Tendo em vista a importância do Casarão Rosa - edifício de valor histórico para a Universidade de Pernambuco, uma vez que corresponde à estrutura que deu origem ao Campus Benfica e à Escola Politécnica de Pernambuco, atualmente denominado Bloco A, o qual é utilizado pela Instituição de Ensino Superior desde o ano de 1937 (SANTOS, 1991) - o presente estudo tem como objetivo apresentar os resultados das inspeções visuais e, do consequente diagnóstico do estado de conservação, porgnóstico, recomendações de eventuais intervenções para a recuperação estrutural e ainda para a proposição de um plano de manutenção periódica, particularmente quanto aos elementos em concreto armado incorporados à edificação histórica ao longo do tempo.

\section{REFERENCIAL TEÓRICO}

\subsection{Patologias das construções}

Assim como os seres humanos, as edificações também sofrem com a ação do tempo, mudanças climáticas e outros males congênitos ou adquiridos. Em vista disto, existe a patologia, ciência responsável por estudar os desvios, sintomas, causas e origens das manifestações patológicas. Na construção civil, é comum se observar a ocorrência de diversas manifestações patológicas, as quais causam desconforto e insegurança aos usuários, além de proporcionar eventuais danos às estruturas. O estudo e tratamento das manifestações devem ser sempre realizados visando a segurança dos usuários e o aumento da vida útil dos edifícios.

\subsection{Vida útil e durabilidade}

Na norma da Associação Brasileira de Normas Técnicas (ABNT), NBR 6118:2014, item 6.2, consta que a vida útil de projeto é o "período de tempo durante o qual se mantêm as características das estruturas de concreto, desde que atendidos os requisitos de uso e manutenção prescritos pelo projetista e pelo construtor".

Conforme consta na ISO 13823:2008, entende-se por vida útil o período de tempo efetivo em que a estrutura ou parte de seus componentes atendem suas funções com um desempenho mínimo de projeto, ausente de algum procedimento de manutenção. O não cumprimento das especificações acarreta reparos e recuperações, ou até mesmo reforço estrutural, os quais poderiam ser evitados se fossem realizados os procedimentos necessários. 
Segundo Souza e Ripper (1998), entende-se durabilidade como o parâmetro que relaciona a aplicação das características de deterioração do material concreto, ou seja, da qualidade do concreto, e dos sistemas estruturais a uma determinada construção, individualizando-a pela avaliação da resposta que dará aos efeitos da agressividade ambiental, qual seja à capacidade de transporte dos líquidos e gases contidos no meio ambiente para a região interior do concreto, e definindo, então, a vida útil da mesma. A durabilidade do material está diretamente relacionada às condições de aplicação e de exposição (THOMAZ, 2009).

\subsection{Manifestações patológicas}

A seguir são definidos os principais conceitos da literatura que se referem às manifestações patologias que costumeiramente afetam as edificações, os quais são essenciais para uma adequada compreensão das manifestações patológicas, bem como do diagnóstico e prognóstico emitidos para o caso em estudo.

\subsubsection{Corrosão de armaduras e do concreto}

A corrosão nas armaduras é uma patologia encontrada frequentemente nas edificações, que de acordo com Melo (2011), ocorrem, pois, o concreto se caracteriza como um sólido compacto e denso, porém com elevada porosidade, permitindo assim a entrada de agentes agressivos, que provocam processos químicos ou eletroquímicos, geradores da corrosão. Iniciado este fenômeno, o aço começa a perder a aderência com o concreto, com a consequente perda de seção e resistência, além da expansão da barra de aço, a qual pode alcançar até oito vezes o seu volume inicial, acarretando a fissuração do concreto e a exposição das armaduras aos agentes agressivos.

Processos de corrosão podem ocorrer nas armaduras e no concreto. Segundo Souza e Ripper (1998), a corrosão das armaduras de aço pode ser classificada em três tipos: por tensão fraturante (fissuras); pela presença de hidrogênio atômico (fragilização e fraturas); e por pite, que pode revelar-se segundo duas formas: localizada (por ação de íons, em especial os cloretos); e generalizada (por carbonatação - redução do pH do concreto para valores inferiores a nove). A corrosão nas barras de aço pode ser o resultado da porosidade do concreto, da existência de trincas e da deficiência no cobrimento das mesmas pelo concreto. A parte oxidada sofre um processo de expansão que expele o concreto do cobrimento e expõe ainda mais as armaduras à agressividade ambiental.

A corrosão do concreto é resultado da ação de agentes ácidos, os sulfatos, o cloro e seus compostos, os nitratos e os nitritos, os quais através da infiltração e do acúmulo ao longo do tempo atacam o concreto (VITÓRIO, 2002). Segundo o autor, com a continuidade do fenômeno de corrosão ao longo do tempo, fatalmente acarretará a total destruição da armação e do concreto, e em última análise poderá causar o colapso da estrutura.

\subsubsection{Desplacamento do concreto}

Vitório (2003) explica o conceito de desplacamento, esfolição ou disgregação do concreto como:

“... ruptura do concreto, em especial nas partes salientes da estrutura. O concreto disgregado geralmente apresenta as características originais de resistência, porém não foi capaz de suportar a atuação de esforços anormais. (Vitório, 2003, p. 32).”

\subsubsection{Eflorescência}

A eflorescência é um processo natural e se apresenta como manchas que aparecem na superfície do concreto, resultado de um processo de lixiviação, o qual a NBR 6118:2014 conceitua como o mecanismo encarregado de transportar os compostos hidratados da pasta de cimento para o exterior da estrutura através de águas puras, carbônicas agressivas, ácidas e outras. As soluções aquosas salinizadas resultantes deste processo, que por meio da capilaridade atravessam o concreto, evaporam e criam depósitos de salinos na superfície. Melo (2011) destaca que para a ocorrência desta patologia é necessária uma constante exposição à umidade, sendo uma ação corretiva a eliminação de tal fator.

Ou ainda, segundo Thomaz (2009), a lixiviação consiste no processo de dissolução e transporte da cal hidratada derivada das reações de hidratação do cimento Portland. Durante o processo de hidratação do cimento são produzidos os cristais de hidróxido de cálcio $(\mathrm{Ca}(\mathrm{OH}) 2)$ e hidróxido de magnésio $(\mathrm{CA}(\mathrm{Mg}) 2)$, os quais são parcialmente solúveis em água, especialmente no caso de água corrente. A lixiviação é nociva ao concreto, tendo em vista que com a remoção de sólidos, ocorre a redução da resistência mecânica do material e abre-se caminho para a entrada de gases e líquidos 
agressivos às armaduras e ao concreto, além da penetração da água e oxigênio que em regra redunda na corrosão de armaduras em peças de concreto armado e concreto protendido (THOMAZ, 2009).

O produto da lixiviação do concreto interage com o gás carbônico $(\mathrm{CO} 2)$ presente no ar e, pode, em certas condições, levar à precipitações e depósitos de sais na superfície da peça de concreto, dentre os quais o carbonato de cálcio e, a consequente formação de crostas e ou manchas de coloração branca, as quais são denominadas eflorescências (NEVILLE, 1997).

\subsubsection{Desagregação do concreto}

Vitório (2003) conceitua desagregação do concreto como:

"É a deterioração, por separação de partes do concreto, provocada, em geral, pela expansão devido à oxidação ou dilatação das armaduras, e também pelo aumento de volume do concreto quando este absorve água. Pode ocorrer também devido às movimentações estruturais e choques. (Vitório, 2003, p. 32)."

\subsubsection{Fissuras}

De acordo com a NBR 6118:2014, fissuras são inevitáveis em estruturas de concreto armado, dado sua alta variabilidade e baixa resistência à tração. A presença delas, desde que a estrutura seja bem executada, respeite as cargas e condições previstas no projeto, não implicam necessariamente na perda de durabilidade da estrutura. A norma informa os limites para as fissuras, que variam de acordo com a Classe de Agressividade Ambiental (CAA) e, o tipo de concreto utilizado. Porém, caso esses fatores não sejam respeitados, elas se tornam porta para os diversos agentes agressivos geradores de manifestações patológicas.

Segundo Vitório (2002), as fissuras são os danos mais observados nas estruturas de concreto e são, de modo geral, causadas pela baixa resistência à tração do concreto. As fissuras representam uma manifestação patológica característica das estruturas de concreto, sendo o dano de ocorrência mais comum e é o que mais chama a atenção dos leigos (SOUZA e RIPPER, 1998). De acordo com Thomaz (2009), as fissuras podem ser causadas por: movimentações térmicas; movimentações higroscópicas; atuação de sobrecargas; deformabilidade excessiva de estruturas de concreto armado; recalques de fundação; retração de produtos à base de cimento; alterações químicas dos materiais de construção; má utilização da edificação; falhas na manutenção; ou ainda por acidentes originados pelos mais diversos fatores tais como incêndios, explosões ou impactos de veículos.

As fissuras são classificadas como mortas ou passivas, quando chegam à máxima amplitude e estabilizam-se frente ao cessar de esforços solicitantes, ou vivas ou ativas, quando são produzidas por ações de magnitude variável e respectivas deformações variáveis no concreto (VITÓRIO, 2002).

\subsubsection{Infiltrações}

As infiltrações consistem na ação de líquidos no interior das estruturas. Há dois tipos básicos de infiltrações, quais sejam: as infiltrações de fora para dentro, quando se referem aos danos causados pelas chuvas ou pelo lençol freático; e as infiltrações de dentro para fora, quando a construção sofre os efeitos de vazamentos ou problemas no sistema hidráulico (ECIVIL, 2018).

A manifestação patológica mais frequente em edifícios é a infiltração e umidade, sendo um dos fatores que possibilitam o desenvolvimento de outras manifestações patológicas na estrutura, pois sua presença implica na lixiviação de componentes do cimento e, consequentemente, o aparecimento de eflorescências. A infiltração também torna a estrutura suscetível à penetração de agentes agressivos, os quais promovem a corrosão nos reforços e o enfraquecimento do concreto. $\mathrm{O}$ fator mais comum para o surgimento da infiltração e umidade é a deficiência do sistema de drenagem do edifício (PITAN et al., 2015).

\subsubsection{Bolor}

Melo (2011, p. 59) conceitua bolor, como: 
“... micro-organismos ou fungos que necessitam de compostos orgânicos como fonte de alimento. Os quais podem ser encontrados na composição de diversos materiais utilizados na construção civil, expostos a ambiente úmido, mal ventilado, mal iluminado ou de clima quente, ou quando o uso de tinta de baixa qualidade, selagem inadequada e pintura sobre o substrato. Esse tipo de manifestação é caracterizado pelo aparecimento de manchas ou pontos pretos, acinzentados ou amarronzados sobre a superfície."

\section{METODOLOGIA}

O estudo foi desenvolvido segundo seis etapas (Figura 1), quais sejam: i) revisão bibliográfica relacionada ao tema; ii) elaboração de desenhos do edifício; iii) inspeção in loco para mapeamento das manifestações patológicas; iv) análise dos dados; v) Compilação dos resultados e relatório fotográfico, a fim da definição do diagnóstico, prognóstico e proposta para recuperação das estruturas em concreto armado; e vi) Elaboração de proposta de um Plano de Manutenção para o edifício, particularmente para as estruturas em concreto armado.

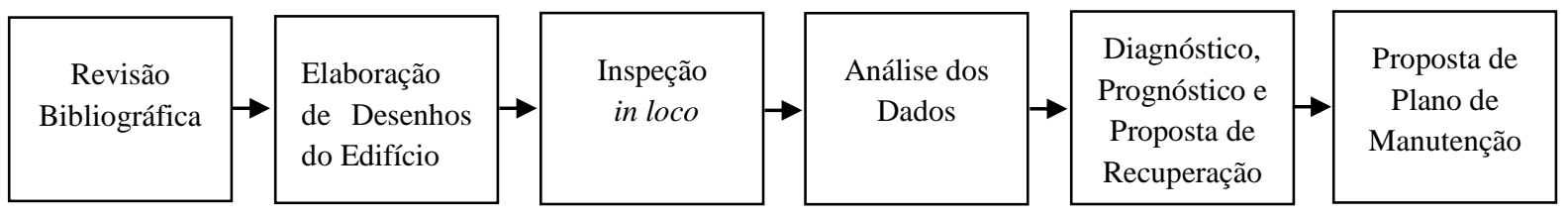

Figura 1: Etapas de desenvolvimento do estudo (AUTORES, 2019).

As inspeções no edifício - Casarão Rosa (Bloco A), foram realizadas nos meses de setembro e novembro de 2019, de maneira visual e com o auxílio de desenhos esquemáticos da edificação e câmera fotográfica, de modo a permitir o mapeamento das possíveis manifestações patológicas e danos estruturais presentes na edificação. Tendo em vista que o Casarão Rosa é uma construção secular, com a inserção de algumas estruturas em concreto armado ao longo do tempo, foi adotada como metodologia para a identificação/confirmação de estruturas em concreto armado a cravação mecânica de pregos em aço, com martelo manual, sobre a superfície da peça em análise - as estruturas em concreto armado oferem resistência à penetração (Figura 2).
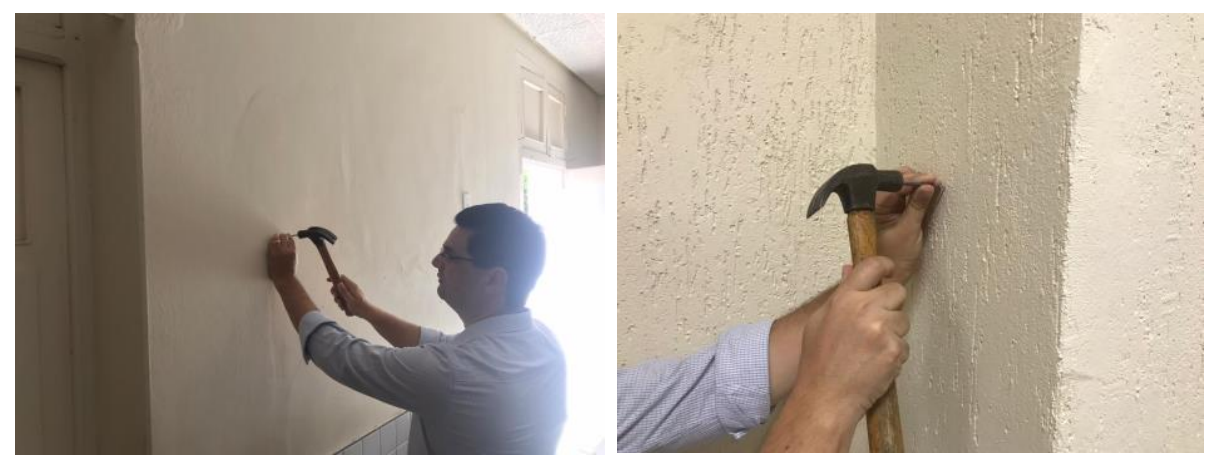

Figura 2: Identifição/confirmação de estruturas em concreto armado (AUTORES, 2019).

Foram consultados os funcionários do setor de manutenção predial da Escola Politécnica a respeito de eventuais intervenções de recuperação e manutenção pelos quais o edifício já havia passado, bem como efetuado os registros de tais informações. Por fim, os dados foram compilados com uso do software Excel, após os quais foram quantificados e analisados. Estes dados permitiram a análise das manifestações patológicas para os elementos construtivos em concreto armado, possibilitando a avaliação preliminar de quais foram os elementos mais deteriorados e os tipos de manifestações patológicas presentes. Para a busca de informações técnicas relevantes foram utilizadas buscas no banco de dados do Google Scholar, Scielo e Portal de Periódicos da Coordenação de Aperfeiçoamento de Pessoal de Nível Superior/Ministério da Educação (CAPES/MEC).

\section{O CASARÃO ROSA}

\subsection{Localização}


A Escola Politécnica de Pernambuco (POLI), parte interante da Universidade de Pernambuco (UPE), está localizada no Campus Benfica, Região Metropolitana do Recife (RMR), bairro da Madalena, cidade do Recife/PE (Firuga 3). A cidade do Recife é caracaterizada por ser uma cidade litorânea, banhada por diversos rios e pelo oceano atlântico, com altas temperaturas médias anuais (clima tropical) e alta umidade relativa do ar e, por consequência, é um lugar potencialmente adequado para a ocorrência de manifestações patológicas sobre os edifícios construídos com baixa qualidade e desempenho.

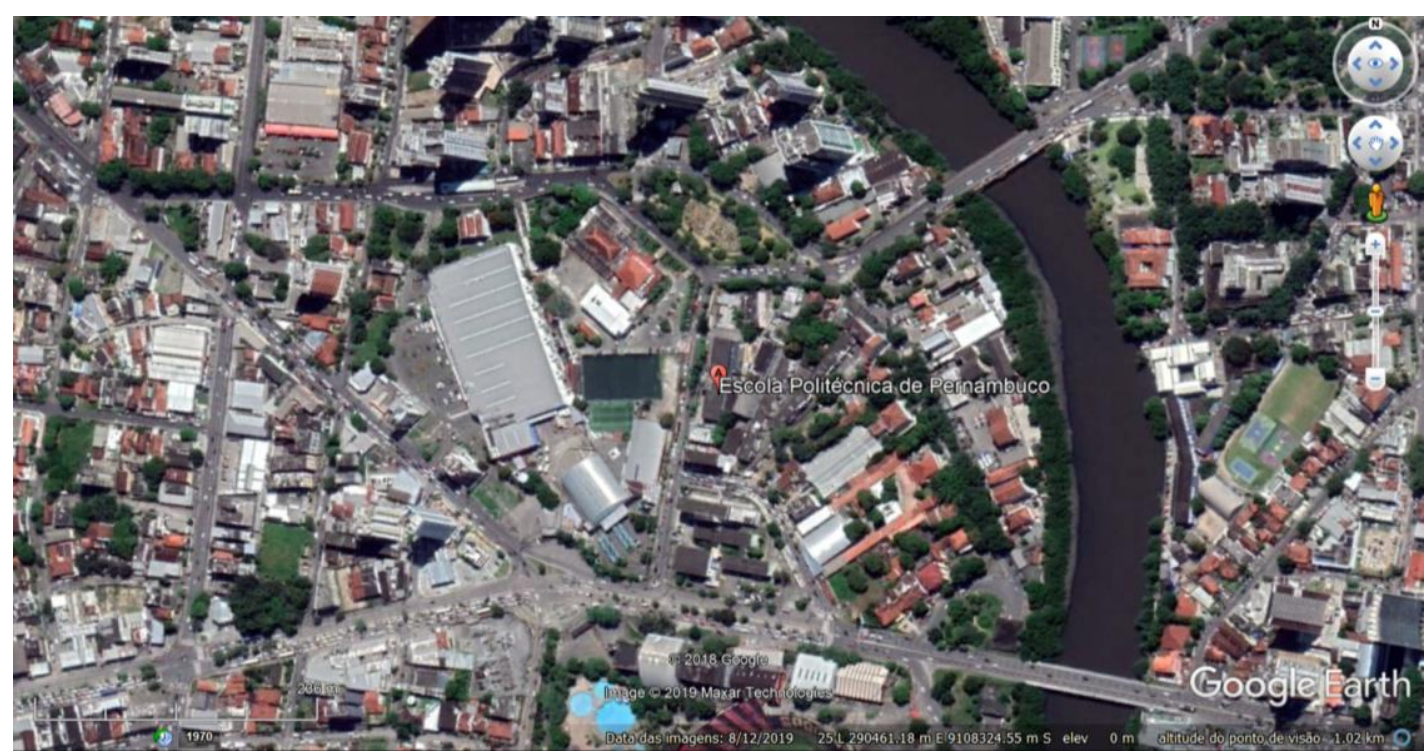

Figura 3: Localização da Escola Politécnica de Pernambuco (AUTORES, 2019).

\subsection{Histórico}

Criada em 6 de março de 1912, durante o governo do General Hermes da Fonseca, na vigência da Lei Rivadávia (SANTOS, 1991) - Decreto n 8659/1911, Lei Orgânica do Ensino Superior e Fundamental, a qual retirou da União o monopólio da criação de Instituições de Ensino Superior (CHAGAS, 1979) - a Escola Politécnica de Pernambuco (POLI) é uma das mais antigas escolas de engenharia do Brasil . Segundo SANTOS (1991), a POLI foi transferida para o número 455 da Rua Benfica e, inicialmente instalada no Casarão Rosa (Bloco A), no ano de 1937, endereço no qual permenece até a presente data (Figura 4).

Transcorridos 82 (oitenta de dois) anos, desde a instalação da Escola Politécnica da Universidade de Pernambuco na Rua Benfica, a seguir é apresentado um breve histórico das intervenções e manutenções pelas quais passou o Edifício Histórico da POLI (Casarão Rosa) ao longo deste período.

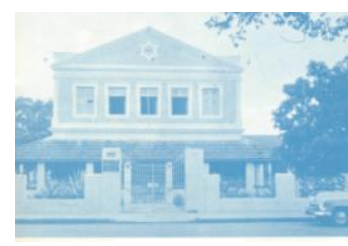

1937

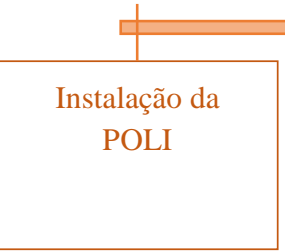

1959

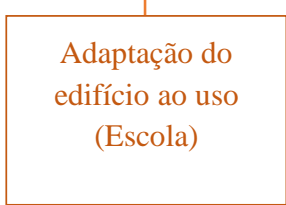

1984

\begin{tabular}{|c|}
\hline Substituição da \\
coberta em \\
madeira por \\
metálica
\end{tabular}

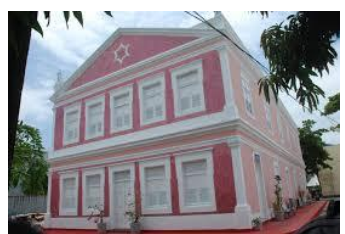

2019

Figura 4: Linha do tempo das intervenções no Edifício Histórico da POLI - Casarão Rosa (AUTORES, 2019). 
Em 1937: Ano de instalação da Escola Politécnica de Pernmabuco, a qual ficou abrigada em um casarão de construção solida, com dois pavimentos, todo em alvenaria, acabamento de primeira, com a frontaria azulejada em róseo, as laterais guarnecidas por alpendres e portas pesadas [...]. No interior, na parte térrea, o piso todo em mosaico inglês; as portas divisórias dos quartos ostentavam bandeiras;[...]. Na parte superior, o piso todo de madeira de lei e travejado, o teto feito em cedro, - enfim, uma construção de bom gosto (SANTOS, 1991).

Em 1959: A Escola utilizara o casarão desde 1937, portanto, havia 22 anos, sem a necessária conservação. Reformá-lo era inadiável. (SANTOS, 1991). [Foram contratados os reparos, os quais] [...] obedeceram a um projeto que, lamentavelmente, não preservou as elegantes linhas coloniais da casa, entretanto, adaptou-a as exigências de uma Escola (SANTOS, 1991). [...] Os consertos constaram mais ou menos de: substituição da escada de madeira nobre por outra construída em cimento armado, revestida de mármore [...]; mudança do forro em cedro por estuques; [...]; alteração da divisão interna; mudança dos pisos de madeira para granito, com fino acabamento, etc. Enfim, transformaram um solar caracterizado pelo esplendor açucareiro em uma casa funcional adaptada a Escola (SANTOS, 1991).

Em 1984: [...] Nessa época, [...] houve um acidente na Escola: o desabamento de parte do teto do Bloco A, provocando sua interdição(SANTOS, 1991, p.54). O Reitor Armando Samico, de pronto, mostrou-se sensível e liberou subsídios [...] para fazer os reparos do Bloco A (SANTOS, 1991). Nessa restauração, foi substituído por estrutura metálica o madeiramento do teto deteriorado pela ação do cupim, alem de terem sido processadas reformas nas divisões internas e de terem sido instalados um pequeno auditório [...], que pode comportar cem pessoas, mais duas salas de aula com capacidade para quarenta carteiras cada uma, e um salão projetado para, receber o Núcleo de Informática da Politécnica — NIP (SANTOS, 1991). Não foram encontrados registros a respeito de eventuais intervenção no BLOCO A após 1984.

Em 2019: É desenvolvido o presente estudo para a análise do estado do Casarão Rosa, particularmente quanto ao estado de conservação do edifício.

\subsection{Caracterização do Casarão Rosa}

O Casarão Rosa (Bloco A) corresponde a um edifício não habitacional de uso especial, escola de engenharia. É composto por pavimento térreo e um pavimento superior, os quais correspondem a uma área total construída de 310,00 $\mathrm{m}^{2}$, na qual estão distruídas salas de aula e administrativas (pavimento térreo) e um auditório (pavimento superior). Sob o ponto de vista estrutural, o edifício é composto por um sistema estrutural preponderantemente em alvenaria resistente de tijolos cerâmicos e, por alguns poucos setores com elementos em concreto armado, incluídos ao longo do tempo, em intervenções para reforma e adequação da edificação. Os pisos internos são revestidos com revestimento cerâmico. As paredes são revestidas com argamassa de cal e areia (áreas externas) e com agramassa de cimento e areia (áreas internas), ou ainda, revestidos externamente com azuleijo na cor rosa (fachada norte) e pintados com tinta acrílica (demais fachadas) e, as paredes internas são pintadas com tinta tipo pva. Os tetos são compostos por forro de gesso e forro em placas minerais (auditório), os quais são pintados com tinta pva. As portas e janelas são em madeira, pintadas com esmalte sintético.

\section{RESULTADOS E DISCUSSÃO}

\subsection{Manifestações Patológicas}

Cosoante dados mapeados quando das inspeções, o Casarão Rosa é composto por 04 (quatro) setores com estruturas em concreto armado, os quais estão ilutrados nos desenhos esquemáticos constantes nas Figuras 5, 6 e 7.

O setor 01 é constituído pelo conjunto estrutural (vigas, laje, patamar e degraus) que compõe a escada de ligação do pavimento térreo ao pavimento superior (fachada oeste), no qual está localizado o auditório - anteriormente havia uma escada em madeira no mesmo local. Os setores 02 e 03 , correspondem à dois pilares em concreto armado situados nas salas de apoio ao auditório, ambas na área interna do mesmo, os quais tem origem no pavimento térreo e se desenvolvem até a cota do forro em gesso do pavimento superior. O setor 04, e último, localizado na fachada sul, corresponde à estrutura da caixa de escada de ligação do pavimento térreo ao pavimento superior, cuja estrutura não compunha a configuração original do Bloco A. 
Os setores com estruturas em concreto armado correspondem a uma área de 57,00 m2, ou ainda, correspondem a $18,0 \%$ da área total construída do Bloco A. As manifestações patológicas mais releventes, bem como a origem, local, sintomas e causas das mesmas, estão sintetizadas na Tabela 1.

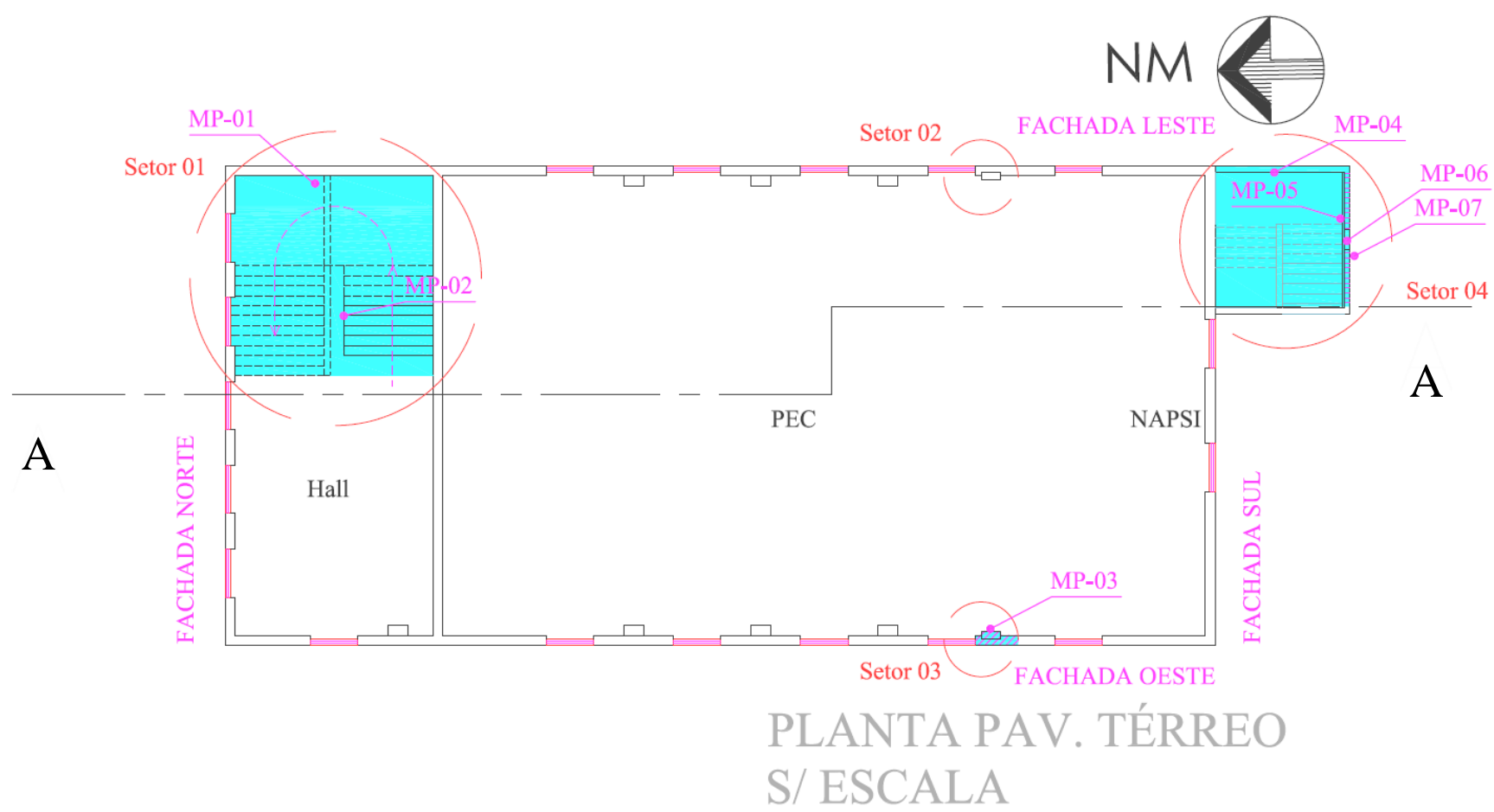

Figura 5: Setores em concreto armado e respectivas Manifestações Patológicas (MP) identificadas (Pav. Térreo)

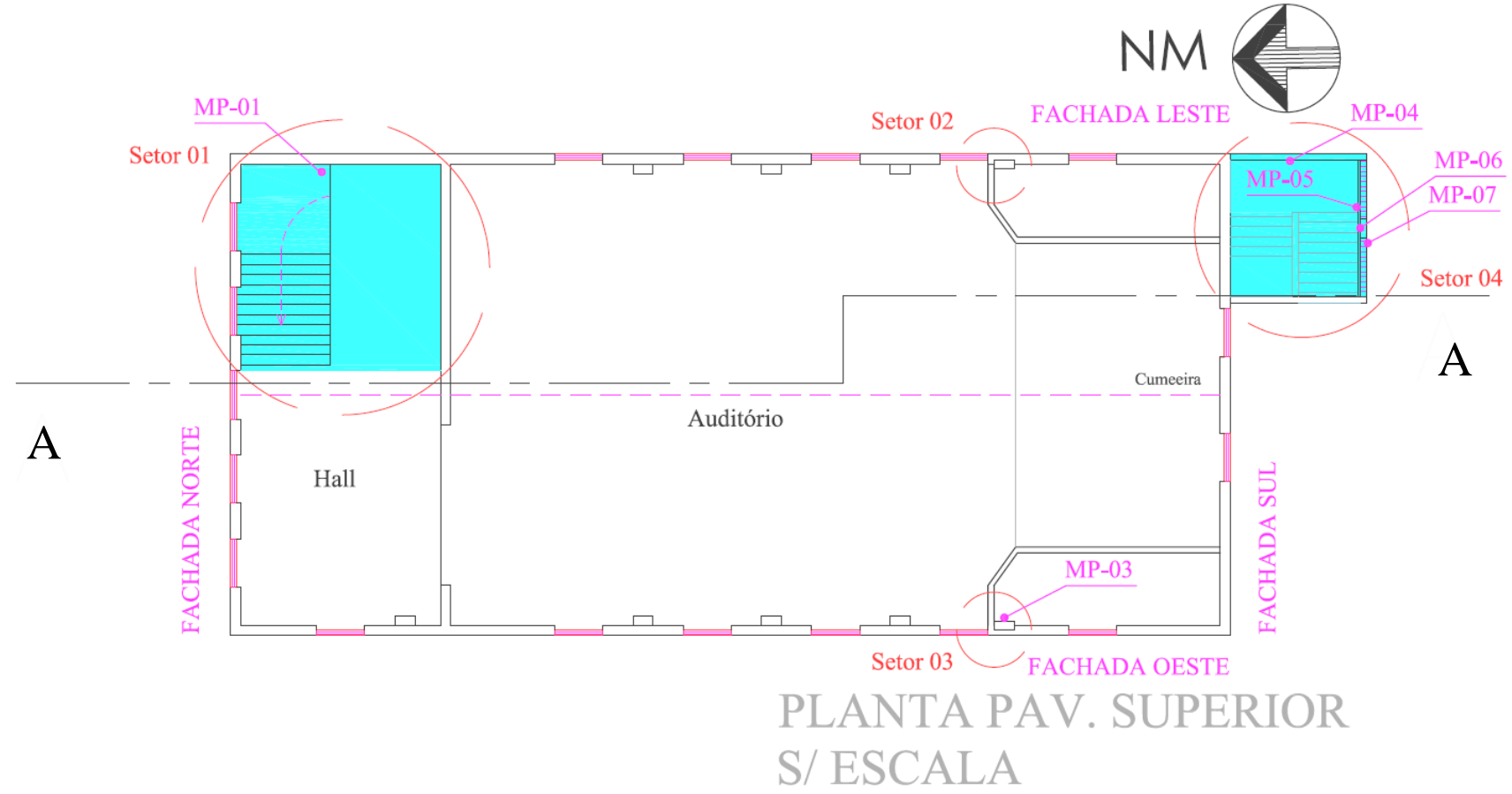

Figura 6: Setores em concreto armado e respectivas Manifestações Patológicas (MP) identificadas (Pav. Superior) 


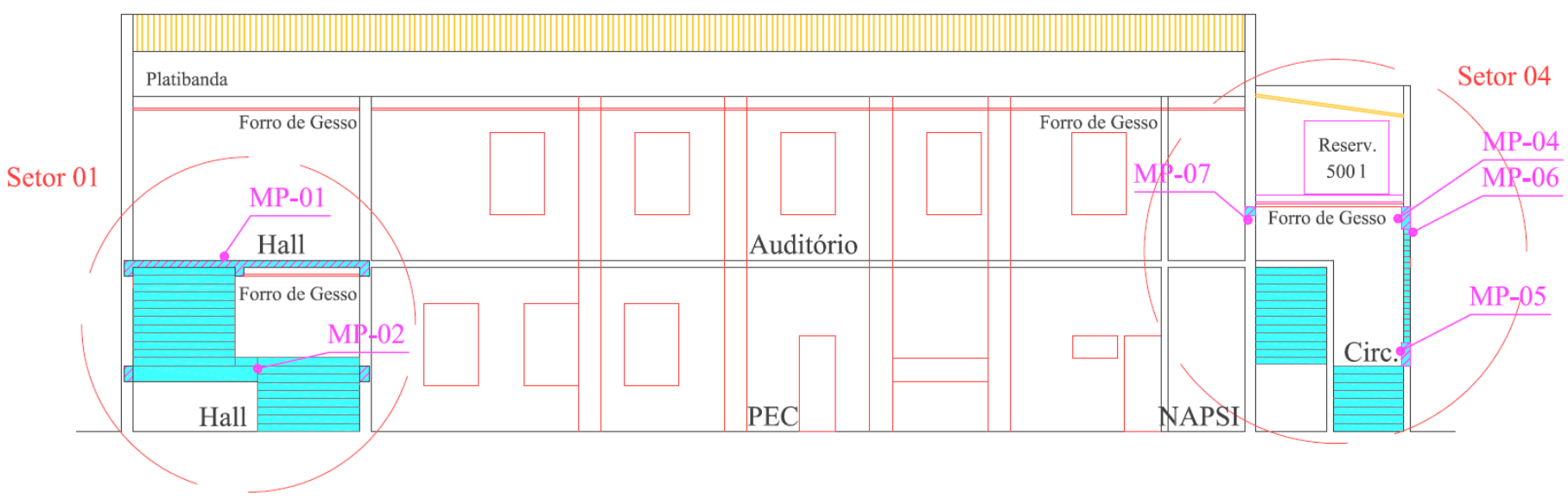

CORTE AA

Figura 7: Setores em concreto armado e respectivas Manifestações Patológicas (MP) identificadas (Corte AA)

Tabela 1 - Manifestações patológicas em estruturas de concreto armado do Casarão (Bloco A)

\begin{tabular}{|c|c|c|c|c|}
\hline Setor & $\begin{array}{c}\text { Manifestação } \\
\text { Patológica }\end{array}$ & Origem & Local/Sintoma(s)/Causa(s) & Registro Fotográfico \\
\hline Setor 01 & MP-01 & Material & 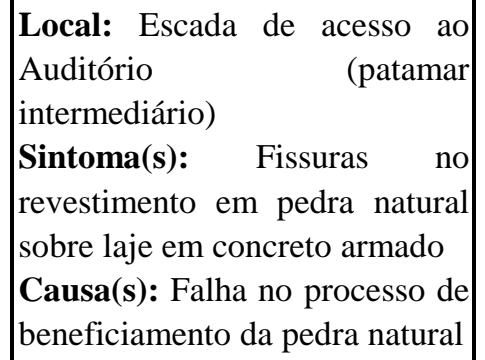 & \\
\hline Setor 01 & MP-02 & Projeto e/ou Execução & $\begin{array}{l}\text { Local: Escada de acesso ao } \\
\text { Auditório }\left(1^{\circ} \text { Lance) }\right. \\
\text { Sintoma(s): Desplacamento de } \\
\text { concreto na aresta entre a face } \\
\text { lateral e inferior da escada } \\
\text { Causa(s): Cobrimento do } \\
\text { concreto insuficiente }\end{array}$ & \\
\hline Setor 01 & MP-02 & Uso & $\begin{array}{l}\text { Local: Escada de acesso ao } \\
\text { Auditório }\left(2^{\circ} \text { Lance) }\right. \\
\text { Sintoma(s): Bolor na face } \\
\text { lateral do degrau } \\
\text { Causa(s): Limpeza e lavagem } \\
\text { inadequadas }\end{array}$ & \\
\hline
\end{tabular}


Tabela 1 - Manifestações patológicas em estruturas de concreto armado do Casarão (Bloco A) (continua)

\begin{tabular}{|c|c|c|c|c|}
\hline Setor & $\begin{array}{c}\text { Manifestação } \\
\text { Patológica }\end{array}$ & Origem & Local/Sintoma(s)/Causa(s) & Registro Fotográfico \\
\hline Setor 03 & MP-03 & Execução & $\begin{array}{l}\text { Local: Pilar na Sala de Som do } \\
\text { Auditório } \\
\text { Sintoma(s): Fissura vertical no terço } \\
\text { médio superior de pilar em concreto } \\
\text { armado } \\
\text { Causa(s): Retração higrotérmica }\end{array}$ & \\
\hline Setor 04 & $\begin{array}{c}\text { MP-04 } \\
\text { (Vista Interna) }\end{array}$ & Projeto e/ou Execução & 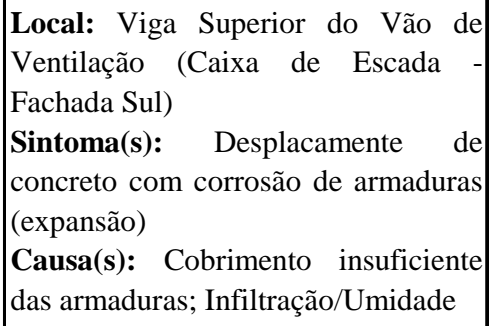 & \\
\hline Setor 04 & $\begin{array}{c}\text { MP-05 } \\
\text { (Vista Interna) }\end{array}$ & Projeto e/ou Execução & 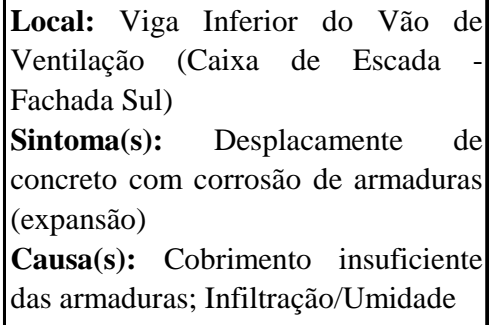 & 8 \\
\hline Setor 04 & $\begin{array}{c}\text { MP-06 } \\
\text { (Vista } \\
\text { Externa) }\end{array}$ & Projeto e/ou Execução & $\begin{array}{l}\text { Local: Viga superior do Vão de } \\
\text { Ventilação da Caixa de } \text { Escada } \\
\text { (Fachada Sul) } \\
\text { Sintoma(s): Fissura horizontal na } \\
\text { transição Viga-Alvenaria e corrosão } \\
\text { de armaduras (expansão) } \\
\text { Causa(s): Ausência de tela na } \\
\text { transição Viga-Alvenaria (absorção } \\
\text { de tensões) e Infiltração/Umidade }\end{array}$ & 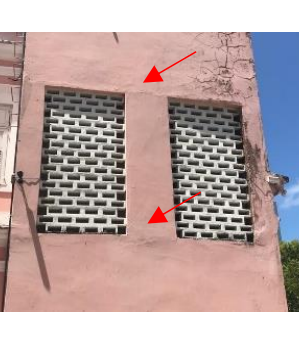 \\
\hline Setor 04 & MP-07 & Projeto & $\begin{array}{l}\text { Local: Viga na transição da Caixa de } \\
\text { Escada/Casarão - Fachada Sul } \\
\text { Sintoma(s): Fissuras na face inferior } \\
\text { de viga em concreto armado } \\
\text { Causa(s): Espaçamento entre } \\
\text { estribos maior do que o necessário ou } \\
\text { inexistentes }\end{array}$ & 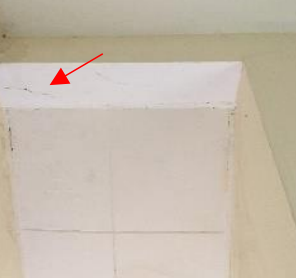 \\
\hline
\end{tabular}

\subsection{Propostas para o projeto de recuperação}

As propostas para o projeto de recuperação das estruturas em concreto armado do Casarão Rosa (Bloco A) - setor 01, setor 02 e setor 04, estão adiante detalhadas na Tabela 2. 
Tabela 2 - Recomendações para o projeto de recuperação estrutural

\begin{tabular}{|c|c|c|c|c|}
\hline Setor & $\begin{array}{c}\text { Manifestação } \\
\text { Patológica }\end{array}$ & Origem & $\begin{array}{l}\text { Recomendações para o } \\
\text { Projeto de Recuperação }\end{array}$ & Registro Fotográfico \\
\hline Setor 01 & MP-01 & Material & $\begin{array}{l}\text { Retidarada do revestimento e } \\
\text { análise complementar para } \\
\text { verificar se o problema é } \\
\text { reflexo de fissuras na base (laje } \\
\text { em concreto armado). Caso } \\
\text { houver fissuras na laje, tratar } \\
\text { com argamassa polimérica e } \\
\text { substituir o revestimento. }\end{array}$ & \\
\hline Setor 01 & MP-02 & Projeto e/ou Execução & $\begin{array}{l}\text { Retirar as partes soltas do } \\
\text { concreto e recompor com } \\
\text { concreto tipo grout. }\end{array}$ & \\
\hline Setor 01 & MP-02 & Uso & $\begin{array}{l}\text { Limpar toda a estrutura de } \\
\text { concreto com água clorada } \\
\text { (água sanitéria) }\end{array}$ & \\
\hline Setor 03 & MP-03 & Execução & $\begin{array}{l}\text { Observar o comportamento da } \\
\text { fissura vertical, tendo em vista } \\
\text { compreender se a mesma é ativa } \\
\text { ou passiva, para definir } \\
\text { enventual intervenção. }\end{array}$ & \\
\hline Setor 04 & $\begin{array}{c}\text { MP-04 } \\
\text { (Vista Interna) }\end{array}$ & Projeto e/ou Execução & \begin{tabular}{|lrrr} 
Demolição & do & concreto \\
fissurado, limpeza & da & armadura \\
com & escova & de & aço. \\
Recomposição & da & armadura \\
com perda & de & seção. \\
Recomposição & da & viga & com \\
grout com combrimento mínimo \\
de 25 mm (ABNT & NBR & 6118, \\
$2014)$ & &
\end{tabular} & 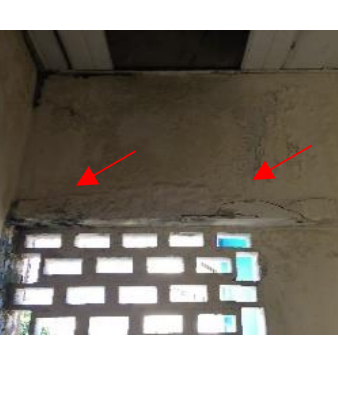 \\
\hline
\end{tabular}


Tabela 2 - Recomendações para o projeto de recuperação estrutural (continua)

\begin{tabular}{|c|c|c|c|c|}
\hline Setor & $\begin{array}{c}\text { Manifestação } \\
\text { Patológica }\end{array}$ & Origem & $\begin{array}{c}\text { Recomendações para o Projeto de } \\
\text { Recuperação }\end{array}$ & Registro Fotográfico \\
\hline Setor 04 & $\begin{array}{c}\text { MP-05 } \\
\text { (Vista Interna) }\end{array}$ & Projeto e/ou Execução & $\begin{array}{l}\text { Demolição do concreto fissurado, } \\
\text { limpeza da armadura com escova de } \\
\text { aço. Recomposição da armadura com } \\
\text { perda de seção. Recomposição da } \\
\text { viga com grout com combrimento } \\
\text { mínimo de } 25 \text { mm (ABNT NBR } \\
6118,2014)\end{array}$ & 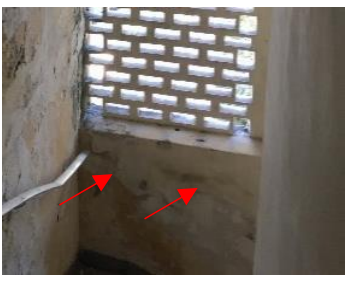 \\
\hline Setor 04 & $\begin{array}{l}\text { MP-06 } \\
\text { (Vista } \\
\text { Externa) }\end{array}$ & Projeto e/ou Execução & $\begin{array}{l}\text { Demolição do concreto fissurado, } \\
\text { limpeza da armadura com escova de } \\
\text { aço. Recomposição da armadura com } \\
\text { perda de seção. Recomposição da } \\
\text { viga com grout com combrimento } \\
\text { mínimo de } 25 \mathrm{~mm} \text { (ABNT NBR } \\
6118,2014)\end{array}$ & 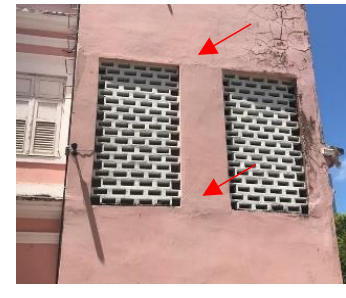 \\
\hline Setor 04 & MP-07 & Projeto & 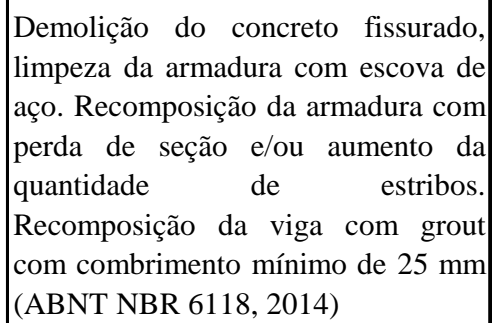 & \\
\hline
\end{tabular}

\subsection{Propostas de Plano de Manutenção}

Tendo em vista que as estruturas do Casarão Rosa (Bloco A) necessitam de cuidados contínuos e planejados, a seguir a apresenta uma proposta de Plano de Manutenção Predial, visando mantê-lo com um bom desempenho e uso pleno. 


\begin{tabular}{|c|c|c|}
\hline Sistema & Serviço & Peridiocidade \\
\hline \multicolumn{3}{|l|}{ 1. Manutenção Predial } \\
\hline Lajes & $\begin{array}{l}\text { Inspeção de possíveis fissuras, trincas, rachaduras, } \\
\text { ferragem aparente, desníveis, corrosão, verificação de } \\
\text { possíveis reparos }\end{array}$ & Semestral \\
\hline Alvenarias & $\begin{array}{l}\text { Inspeção e verificação de possíveis necessidades de } \\
\text { reparos }\end{array}$ & Semestral \\
\hline $\begin{array}{l}\text { Elementos em Concreto } \\
\text { Armado (Vigas, Pilares) }\end{array}$ & Inspeção, verificação e reparos & Mensal \\
\hline Coberta & Limpeza das coberturas & Mensal \\
\hline \multirow{2}{*}{ Impermeabilização } & Inspeção geral e reparos & Mensal \\
\hline & Limpeza e reparos & Mensal \\
\hline Calhas & $\begin{array}{l}\text { Inspeção, melhoria da fixação, tratamentos e troca de } \\
\text { chapas oxidadas, correção de caimentos, limpeza das } \\
\text { calhas, desobstrução de condutores }\end{array}$ & Mensal \\
\hline Pisos & Inspeção / reparos & Anual \\
\hline Reboco & Inspeção / reparos / recomposição & Anual \\
\hline Forros & Inspeção / reparos / recomposição & Anual \\
\hline Pintura interna e externa & Inspeção / reparos / recomposição & Anual \\
\hline $\begin{array}{l}\text { Esquadrias, caixilhos, } \\
\text { portas }\end{array}$ & Inspeção / reparos & Anual \\
\hline $\begin{array}{l}\text { Ferragens (dobradiças, } \\
\text { maçanetas/fechaduras, } \\
\text { molas, grelhas, fechos) }\end{array}$ & Inspeção / lubrificação / regulagem/substituição & Semestral \\
\hline $\begin{array}{l}\text { Vidros, } \\
\text { espelhos, }\end{array}$ & Inspeção / reparos & Semestral \\
\hline
\end{tabular}

\section{CONCLUSÕES}

Os resultos obtidos permitem compreender que os problemas críticos nas estruturas são pontuais, especialmente nas vigas quem compõem a caixa de escadas da fachada sul. Ações de recuperação das estruturas devem ser tomadas de forma breve, sob pena do aumento dos custos para e recuperação estrutural. Um plano de manutenção para as estruturas de concreto armado é sugerido, visando manter o Casarão Rosa com um bom desempenho e uso pleno.

É recomendado para os próximos estudos uma investigação, mais aprofundada, a respeito de enventuais setores que contenham estruturas em concreto armado não identificadas no presente estudo.

\section{AGRADECIMENTOS}

Aos funcionários da Escola Politécnica de Pernambuco, responsáveis pela manutenção predial, os quais acompanharam as inspeções e forneceram informações relevantes à consecução do presente estudo.

\section{REFERÊNCIAS}

ASSOCIAÇÃO BRASILEIRA DE NORMAS TÉCNICAS (ABNT). NBR 6118: Projeto de estruturas de concreto Procedimento. Rio de Janeiro, 2014. 170 p

CÂMARA BRASILEIRA DA INDÚSTRIA DA CONSTRUÇÃO - CBIC. Desempenho de Edificações Habitacionais: Guia Orientativo para Atendimento à Norma ABN NBR 15575/2013. 2. ed. Fortaleza, 2013.308 p.

CHAGAS, V. Didática Especial de Línguas Modernas. São Paulo: Companhia Editora Nacional, 1979. 


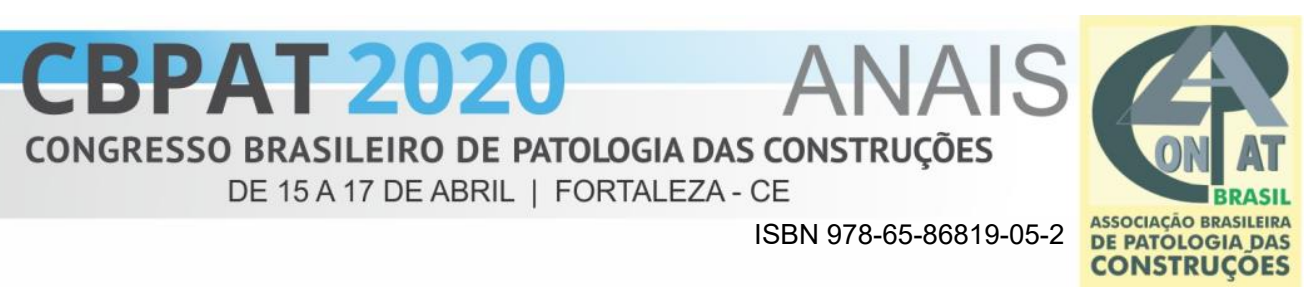

EMPRESA BRASIL DE COMUNICAÇÃO - EBC. Completa um mês tragédia da Muzema, no Rio. Disponível em: <http://agenciabrasil.ebc.com.br/geral/noticia/2019-05/completa-um-mes-tragedia-da-muzema-no-rio>. Acesso em: 26 out. 2019.

G1. Laudo sobre desabamento de prédio em Fortaleza deve ser concluído em 10 dias. Disponível em: <https://g1.globo.com/ce/ceara/noticia/2019/10/21/pericia-inicia-investigacao-sobre-desabamento-do-edificio-andreaem-fortaleza-bombeiros-darao-apoio.ghtml>. Acesso em: 26 out. 2019.

PITAN, N. M.; BERENGUER, R. A.; SILVA, A. J. C.; LINS, C. M. M. S.; MONTEIRO, E. C. B. Pathological Manifestations and the Study of Corrosion Present on Bridges of the City of Recife. EJGE. v. 20, p. 11893-11907, 2015.

SOUZA, V. C. M.; RIPPER, T. Patologia, Recuperação e Reforço de Estruturas de Concreto. São Paulo: PINI, 1998.

VITÓRIO, J. A. P. Pontes rodoviárias: fundamentos, conservação e gestão. Recife, CREA-PE, 2002. 